\title{
Static Shear Response of Recycled Carbon Fibre Composites
}

\author{
Karthik Krishna Kumar ${ }^{\mathrm{a}}$, Allan Hutchinson ${ }^{\mathrm{a}}$, James Broughton ${ }^{\mathrm{a}}$ \\ a School of Engineering, Computing and Mathematics, Oxford Brookes University, Oxford, \\ U.K.
}

\begin{abstract}
The specification and use of recycled carbon fibre $(\mathrm{rCF})$ composites requires the generation of data that can give a comprehensive description of the material system. The propertyconstituent relationships of discontinuous short-fibre composites requires the development or adaptation of material testing practices, coupled with an understanding of the failure mechanisms. Our research dealt with an experimental study of recycled, discontinuous, needle-punched, non-woven carbon fibre/epoxy composites. The object was to define a test protocol that could be used to determine the shear load limits. Four different interlaminar shear test methods were investigated, namely, Short Beam Shear, Double Notch Shear, Double Beam Shear and Iosipescu Shear for two laminates of different fibre volume fractions. Identification of the weakest shear plane in the composite and re-fabrication of the specimen geometry enabled consistent interlaminar shear failures using the Iosipescu Shear test method. A modified Iosipescu shear specimen provided a stress state in the composite that was much closer to pure interlaminar shear than that observed with other test methods, where the specimens are subject to more complex stresses. We found that the shear behaviour of the rCF was related to the internal fibre architecture of our particular material, thus enabling potential optimisation of such composites.
\end{abstract}

\section{Keywords:}

Recycled Carbon Fibre, Non-woven Composite, Modified Shear Testing, Interlaminar Shear 


\section{Introduction}

The rapid rise in carbon fibre composite usage in recent years has a large impact on sustainability issues and this has led to the development of carbon fibre recycling technologies such as solvolysis [1-3], hydrolysis [4-6], fluidised bed pyrolysis [7-9] and chain conveyor pyrolysis [10-12]. The critical technological challenge with recycled fibres is the inability to replicate the reinforcement structure of the virgin composite system [13]. The recycled carbon fibres are generally fluffy, tangled and difficult to handle and need further processing. Currently, they are converted into randomly dispersed, discontinuous, non-woven reinforcement mats and reproduced into composite laminates by compression moulding techniques [14]. The major barriers to the adoption of rCF composites have been the lack of a credible knowledge base and the unsuitability of standards and test protocols that adequately represent them. Several test methods exist for measuring the same property but while some are easy to use they can produce unreliable results, whereas more complex test methods produce more reliable results with appropriate operator skills. The challenge lies in the identification or development of a methodology that can generate conclusive data. The continuous emergence of new composite forms, that do not respond to loads in the same manner as the ones developed earlier, makes it difficult to generate a database and standardized test scheme for the composite family [15].

As many industries begin to rely more heavily on composites and bonded materials, reliable and accurate shear testing is essential [16]. The anisotropic nature of composites mean that it is critical to understand the shear response including in-plane shear and out-of-plane shear. In addition to the material structural capabilities, shear testing can be devised to assess the fibre-matrix interface bond quality and the quality of the bond between the composite plies. The random dispersion of recycled fibres in the composite structure imply that the shear characteristics strongly depend on how the composite is loaded with respect to the principal 
fibre directions. It is hence more critical to compute the weaker interlaminar shear over inplane shear because the reinforcement architecture would provide additional in-plane and biaxial mechanical strength in the XY shearing planes (Fig 1). Many test methods have been developed to measure both in-plane shear and out of plane shear such as Short Beam Shear (SBS) [17, 18], Double Notch Compression [19], Double Beam Shear [20], Iosipescu shear [21], 10 or 45 degree off axis tensile test [22], two-rail shear [18], etc. However, getting reliable and repeatable data is of particular concern in the selection of test methods for $\mathrm{rCF}$ composites.

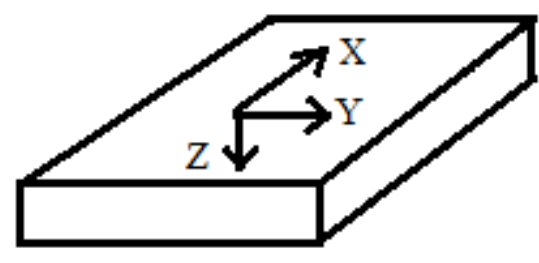

Figure 1 - Laminate plane notations in the $X$ direction (warp), $Y$ direction (weft), and $Z$ direction (thickness)

The difficulty with a majority of interlaminar shear test methods is to achieve a state of pure and uniform shear over the gauge region repeatedly for that specific material under examination. Judging the validity of a test at the composite level is more difficult than at the fibre level. The SBS test is a popular, widely known and quick method to determine the apparent interlaminar shear strength of a composite but shear failure is rarely achieved. It may be required to alter the specimen geometry or the test procedure even for continuous fibre reinforcements, as had been done for the SBS test by reducing the surface area of shear failure by introducing a longitudinal notch [23], use of a thick beam [24] and bonding the laminate between strips of metallic plates [25] to facilitate interlaminar failure. Another variant of the SBS test is the double beam shear (DBS) test that was reported to produce interlaminar failure in unidirectional (UD), cross-ply and quasi-isotropic composite layups by 5 point bending, failing to produce any delaminations by the SBS test [26]. The shear 
properties of a composite laminate as determined by an Iosipescu shear test depend on the material orthotropy and, to accommodate this, the optimal V-notch angle of an Iosipescu specimen is rescaled by Equation 1:

$$
\tan \theta=\frac{\tan \theta_{\text {iso }}}{\sqrt[4]{E_{2} / E_{1}}}
$$

where $2 \theta_{\text {iso }}=110^{\circ}$ and $\mathrm{E}_{2}$ and $\mathrm{E}_{1}$ are elastic moduli along the principal directions of the laminate being tested $[27,28]$. Acceptable in-plane shear failure, characterised by a notch-tonotch crack, is captured in composites with layups of continuous fibre reinforcements of $[0]_{s}$, $[90]_{\mathrm{s}}$, or $[0 / 90]_{\mathrm{s}}$ specifically along the $0^{\circ}$ direction but resorts to a tensile failure characterised by a crack at $45^{\circ}$ from the notch axis when switched to a random reinforced mat [29-32]. This is also true for 3D textile composites where a 4 notch Iosipescu specimen was developed because of the lack of inherently weak shear strength planes in the material [33]. In-plane shear failure is plausible in laminates with a higher degree of anisotropy than random fibre reinforced composites due to the influence of normal stresses in the gauge section of the specimen. The use of Iosipescu shear for the determination of out-of-plane shear or interlaminar shear, along the $\mathrm{XZ}$ and $\mathrm{YZ}$ planes, have been seldom reported because of the difficulties involved in manufacturing a thick composite laminate and the catastrophic failure in transverse tension along notch flanks for UD specimens [34-36]. The Iosipescu shear strength of a UD laminate along the $0^{\circ}$ direction is numerically equal to the throughthickness shear strength and hence testing in the XZ plane is rarely used in practice [21]. Along the $90^{\circ}$ direction of a UD laminate, the common observation of failure is a sequence of horizontal cracks and splitting of fibres near the top and bottom notch roots followed by horizontal cracks between the notches in the gauge section. Few authors recommend increasing the angle of the $\mathrm{V}$ notch as per Equation 1 to induce horizontal delamination cracks in the gauge section between the notches, but it was shown that the stresses associated 
with the initial horizontal splitting and the ultimate shear failure are relatively close to each other. Furthermore, the point of failure of the material to be considered as representative for the material is debatable and the shear strength of the material should be linked with the first delamination or horizontal splitting observed rather than the ultimate strength $[21,28,37]$. Although these arguments may hold for UD composites, it could be understood that for nonwoven and other textile composites, achieving shear failure and the material response to shear loads depend heavily on the nature of the composite reinforcement and the plane of load introduction into the test specimen.

Another alternative to measure interlaminar shear is the double notch shear (DNS) test and it has been shown that the shear strengths from the Iosipescu shear test and DNS shear test along the $\mathrm{XZ}$ plane are identical in a UD CF/epoxy composite [21]. The DNS test remains a simple and reliable method for interlaminar shear characterisation on the condition that the failure of the specimen occurs as a longitudinal notch-to-notch crack signifying the delamination of the laminate due to a compression load. Consistent shear failures have been reported in CFRP and GFRP based UD and cross-ply fibre systems [29, 38] and it was later recommended that a 90 degree lay-up be used to induce pure interlaminar shear in the gauge section of the specimen [39]. However DNS has a lot of drawbacks including poor stress uniformity, high stress concentrations at the notch and dependence on the notch distance and depth that led to the development of inclined double notch shear test [21, 40, 41]. In the event of an interlaminar shear failure, the cause of failure could be the breakdown of the fibre-matrix interface, a matrix failure, delamination between the plies, or a combination of them depending on the interfacial strength between the fibre and the matrix and the shear strength of the matrix which makes interpretation of the experimental results complicated. Composites are sensitive to specimen preparation techniques and the quality of the specimens prepared for mechanical testing is of utmost importance as they influence the reproducibility 
and reliability of test results [42]. The purpose of our research was to realise 'true' interlaminar shear failure in the $\mathrm{XZ}$ and $\mathrm{YZ}$ planes (Figure 1) for recycled, discontinuous, non-woven composites that could be useful to develop design data with reasonable accuracy and define appropriate shear test methodology for this class of composites. The variability of results, failure mode of the specimens and the data obtained from the above testing methods were analysed and the validity of these test methods was assessed.

\section{Materials and Methods}

Material used:

The shear characteristics of rCF/epoxy composite manufactured by ELG Carbon Fibre Ltd. was investigated in this study at the coupon level. Two laminates of $2 \mathrm{~mm}$ and $6 \mathrm{~mm}$ thicknesses, corresponding to 0.21 and 0.35 fibre volume fractions respectively, ascertained by an optical sectioning method reported elsewhere [43], were used in this study. The plies comprised of 200 gsm dry non-woven mats based on fibres recovered via pyrolysis, which are porous in nature. The non-woven fabric is unbalanced with respect to the fibre volume content in longitudinal $(\mathrm{X})$ and transverse $(\mathrm{Y})$ directions in the $\mathrm{XY}$ plane due to the slightly preferential dispersion of the discontinuous recycled fibres in the weft direction over the warp by the textile processing carding mill. Furthermore, during the carding stage of the nonwoven mats, the fabric is consolidated in the $\mathrm{Z}$ direction by a needle punching process. The mat with the tradename CARBISO ${ }^{\mathrm{TM}} \mathrm{M}$ (Figs 2 and 3), is made of approximately $80 \mathrm{~mm}$ long discontinuous fibres with the code name SM45D [44]. The laminates were then moulded from their non-woven fabrics in epoxy matrix by sheet moulding compounding (SMC) technique.

Laminates of $2 \mathrm{~mm}$ thickness made of 4 plies of non-woven mats were used for the SBS, DNS and DBS test methods to maximise matrix based shear failure whereas a $6.2 \mathrm{~mm}$ thick 
laminate made up of 20 plies were used for the SBS, DBS and the Iosipescu test for which the laminate needed to be remanufactured into appropriate specimen geometries in accordance to the plane of testing. All of the tests were run on a Testometric M500-50CT Universal Tester at room temperature conditions and a crosshead displacement speed set at 1 $\mathrm{mm} / \mathrm{min}$.
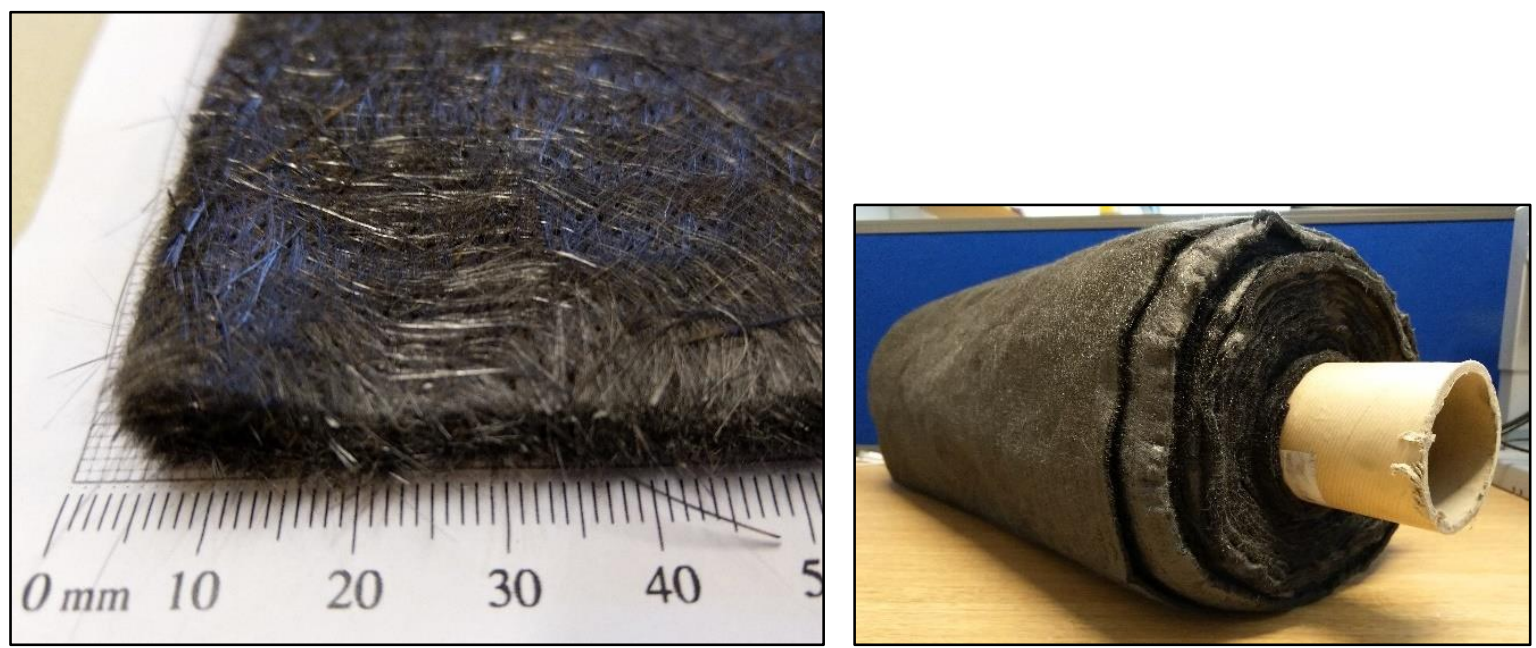

Figure 2 - Non-woven mats made of recycled, discontinuous, randomly dispersed fibres
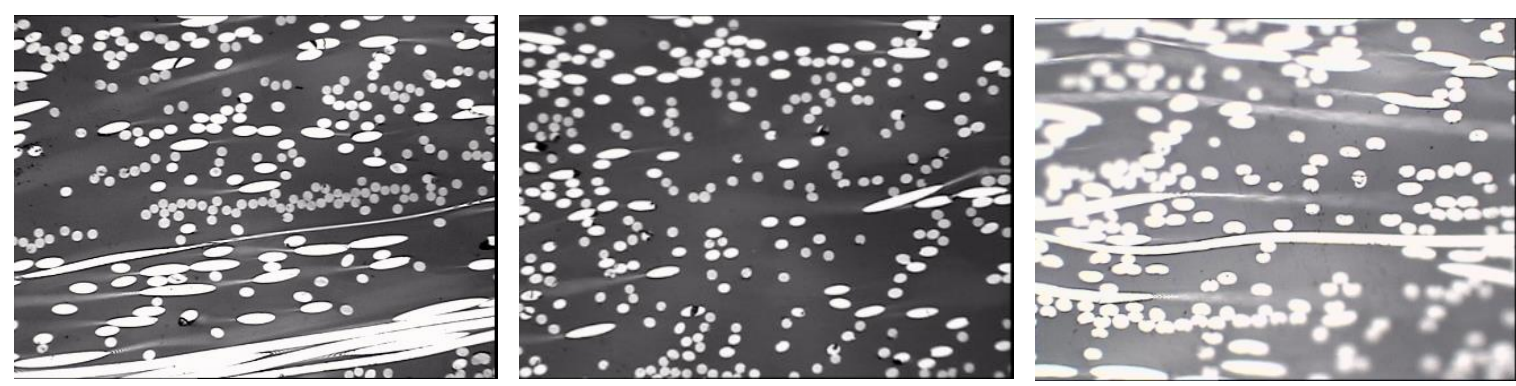

Figure 3 - Micrographic sections at 50x magnification depicting typical fibre distribution in the rCF/epoxy laminate

Shear test methodologies:

\section{Short Beam Shear (SBS)}

The SBS test method by three point bending, as described by ASTM D2344 [18] and ISO 14130 [17], was used to determine the interlaminar shear strength (ILSS) in the XZ (or YZ) plane of the composite laminate by the use of a short beam specimen with a small span to thickness ratio. The specimen of dimensions shown in Figure 4Figure 4- Schematic of Short 
Beam Shear specimen and the test was subjected to three point bending, with the objective of maximizing shear in the central region of the specimen. The apparent interlaminar shear stress is calculated from the beam theory using equation 2 :

$$
\tau=\frac{3 \mathrm{~F}}{4 \mathrm{bh}}
$$

where $\mathrm{F}$ is the failure load in $\mathrm{N}, \mathrm{b}$ and $\mathrm{h}$ are the width and thickness of the test specimen in millimetres and $\tau$ is the shear strength in MPa. Both the ASTM D2344 and ISO 14130 use the same principles but differ slightly with specimen geometry and experimental set up as summarised in Table 1. It is required that the specimens fail by an interlaminar crack in the mid-plane of the beam for an acceptable result.

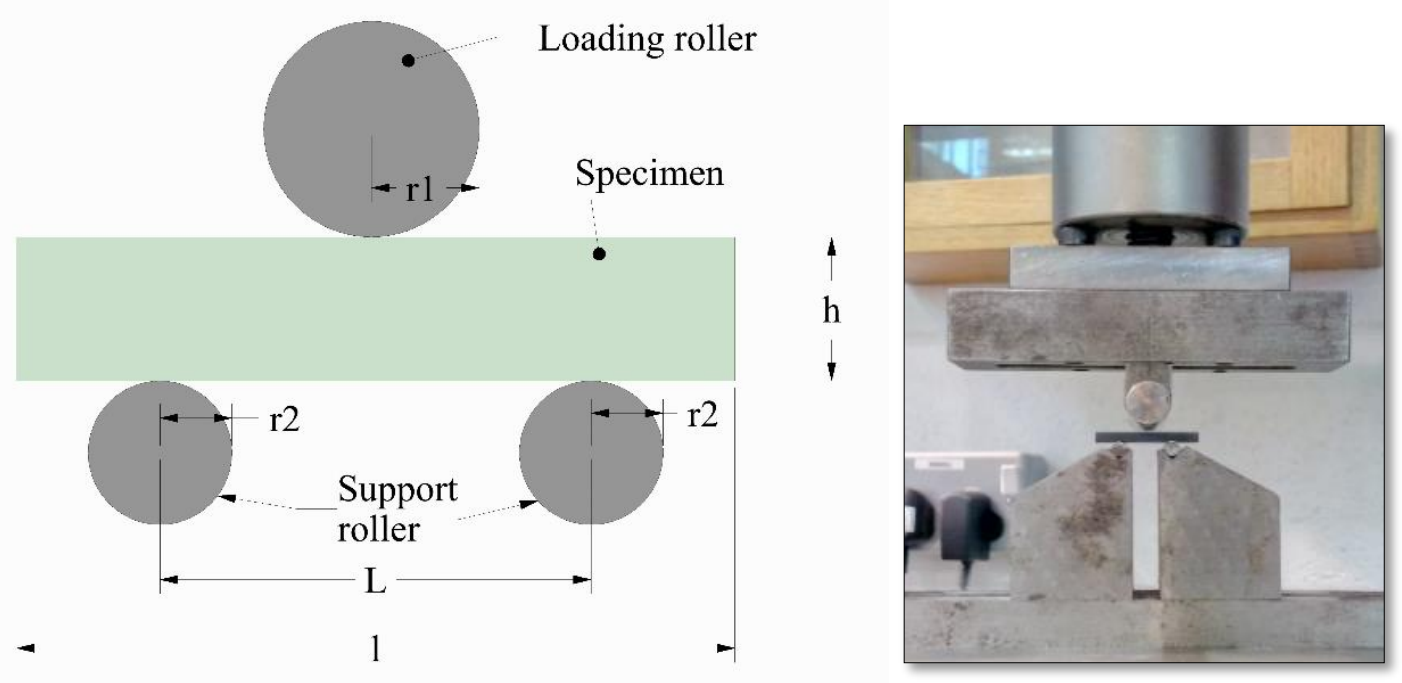

Figure 4- Schematic of Short Beam Shear specimen and the test apparatus

\begin{tabular}{ccc}
\hline Parameter & ASTM D2344 & ISO 14130 \\
\hline $\mathbf{r 1}$ & $3 \mathrm{~mm}$ & $5 \mathrm{~mm}$ \\
\hline $\mathbf{r 2}$ & $1.5 \mathrm{~mm}$ & $2 \mathrm{~mm}$ \\
\hline L/h & 4 & 5 \\
\hline Table 1- Fixture dimensions of Short Beam Shear Test
\end{tabular}




\section{Double Notch Shear (DNS)}

The DNS test method is used to estimate the through-the-thickness shear strength of thermoset and randomly dispersed fibre reinforced composites as specified by ASTM D3846 $-08[19,45]$. An axial compressive load was applied onto the edge of a double notched specimen of length $79.5 \mathrm{~mm}$, thickness $2 \mathrm{~mm}$ and width of $12.7 \mathrm{~mm}$ as shown in Figure 5 that was firmly held in a supporting jig to prevent buckling of the test specimen. The experimental apparatus was manufactured in house. The notches were machined to half the thickness of the specimen and were centrally located on opposite faces of the specimen spaced at a distance of $6.4 \mathrm{~mm}$ with a diamond coated saw. The compression load was applied at a test speed of $1 \mathrm{~mm} /$ minute and was carried out at ambient laboratory conditions. The shear failure as per the DNS test is characterised by a crack along the shearing plane between the staggered notches of the specimen. The shear strength of the material in the ZX (or ZY) plane is defined as the ratio of the maximum load carried by the specimen until rupture during the test to that of the shear area between the notches.

\section{Double Beam Shear (DBS)}

The DBS method was developed to determine the interlaminar shear of composite laminates in the XZ (or YZ) plane of the composite laminate and is specified in BS ISO 19927:2018 [20]. A short beam specimen was subjected to a 5 point bending load as shown in Figure 6 with the use of cylindrical rollers that have a contact diameter of $6 \mathrm{~mm}$. Rectangular cross section specimens of thickness $2 \mathrm{~mm}$, length $30 \mathrm{~mm}$ and width $10 \mathrm{~mm}$ was used for the $2 \mathrm{~mm}$ thick laminate. The width and length for the $6 \mathrm{~mm}$ thick laminate were set to 5 times and 15 times the thickness respectively. The beam is supported by three equidistant rollers based on the thickness of the beam used and is loaded on by two other rollers at a test speed of 1 $\mathrm{mm} /$ minute until specimen failure. The shear failure is defined by delaminations or 
interlaminar failure on the mid-plane region of the specimen. The shear strength, derived from the classical beam theory, is determined from equation 3.

$$
\tau=\frac{33 F}{64 b h}
$$

where $\mathrm{F}$ is the critical failure load in $\mathrm{N}, \mathrm{b}$ and $\mathrm{h}$ are the width and thickness of the test specimen in millimetres and $\tau$ is the shear strength in MPa.

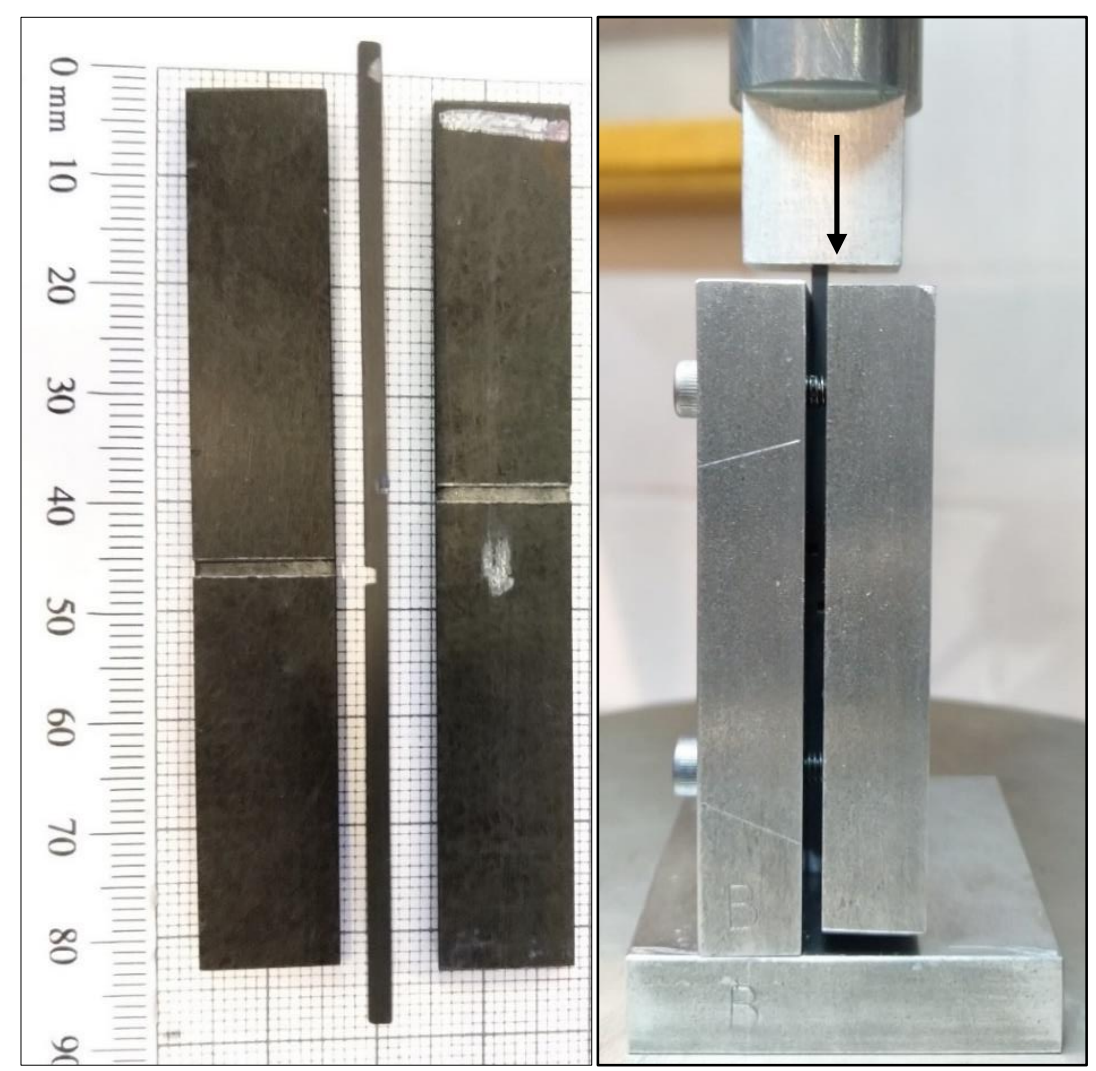

Figure 5- Double Notch Shear Apparatus 


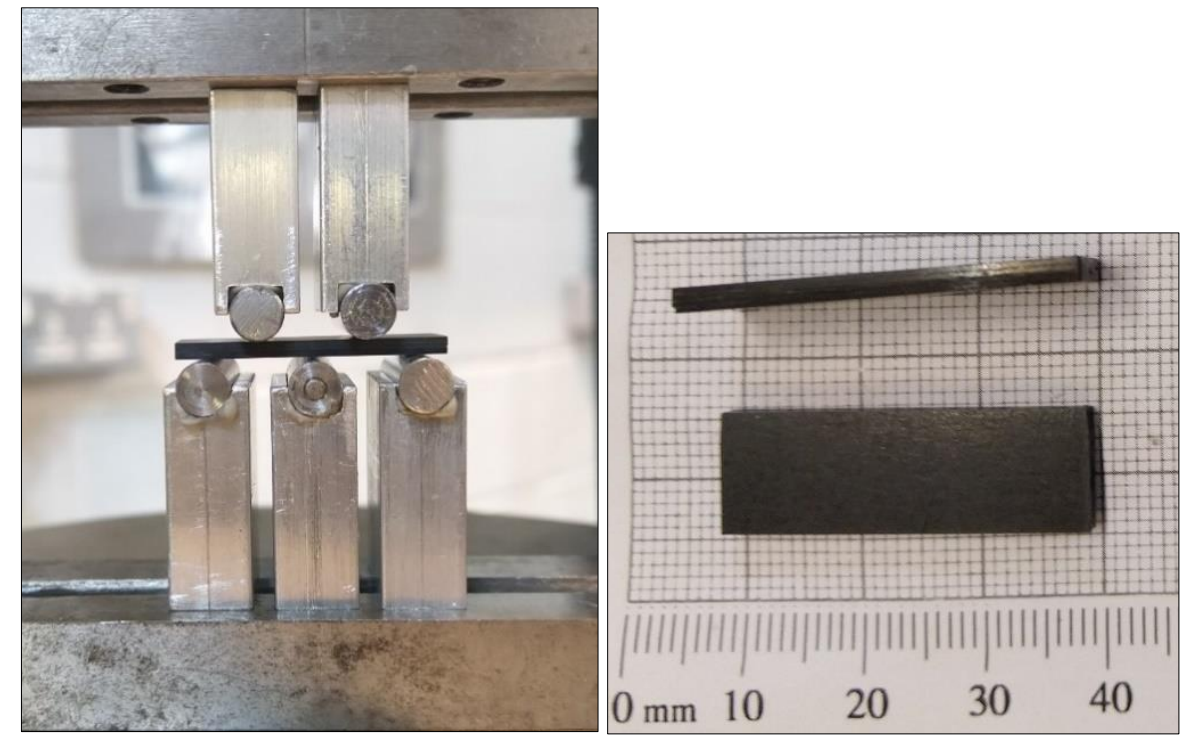

Figure 6 - Double Beam Shear Apparatus and Specimen Geometry

\section{Iosipescu Shear}

Iosipescu shear can be used for determining the in-plane shear and out-of-plane shear of the composite material based on the direction the laminate is being tested in. The Iosipescu shear test experimental set up is shown in Figure 7. The standard test method uses a prismatic rectangular specimen of dimensions $\left(80 \times 20\right.$ x specimen thickness) $\mathrm{mm}^{3}$ with symmetric $90^{\circ}-\mathrm{V}$ notches through the height and loaded asymmetrically in compression to maximise shear between the notches [21]. The specimen rests on the back face of the Iosipescu fixture to reduce specimen twisting, with the notch aligned at the centre between the two grips. The relative movement of the moving upper grip to the fixed lower grip induces a shear strain between the notches along the direction of compression and shear failure is either characterised as a notch to notch crack in conventional continuous fibre reinforced $0^{\circ}$ UD composites or the presence of horizontal cracks in $90^{\circ}$ direction specimens. The upper grip movement is facilitated by the crosshead of a $50 \mathrm{kN}$ Testometric testing equipment at a speed of $1 \mathrm{~mm} / \mathrm{min}$. The in-plane Iosipescu shear specimens (XY plane) were prepared as per ASTM D5379 by water-jet cutting from the composite laminate. The ratio of the maximum 
force at failure to the cross sectional area between the notches is taken as the shear strength of the material.

The out-of-plane shear or interlaminar shear in the ZX (or ZY) plane was determined by remanufacturing the central gauge section of the standard Iosipescu specimen by bonding three $6 \mathrm{~mm}$ thick cured laminates onto each other with epoxy, the $90^{\circ}-\mathrm{V}$ notch cut using an end mill tool and completing the length of the Iosipescu geometry by symmetrically bonding $6 \mathrm{~mm}$ thick rectangular laminate blocks oriented in the $\mathrm{XY}$ plane to the prepared gauge section (Fig 7). The out-of-plane shear or interlaminar shear in the XZ (or YZ) plane was determined by bonding $6 \mathrm{~mm}$ thick cured laminates over each other until the required width of the Iosipescu geometry is achieved and the V notches were cut out by an end mill tool (Fig 8). The V notches were cut at $90^{\circ}$ for one set of specimens and at $135^{\circ}$ for another set corresponding to Equation (1). In the XZ (or YZ) plane, the shear strength is determined from the strength at the first occurrence of delamination or splitting in the specimen. The selection of a $6 \mathrm{~mm}$ thick laminate for out-of-plane shear facilitates the $\mathrm{V}$ notch to be cut within one laminate and prevent its penetration or the root end of the V notch at the bond lines between the laminates. It was ensured in all cases that the generation of the $\mathrm{V}$ notch did not produce any micro-cracks in the specimen by examination under a microscope.

The shear modulus of the material was determined with the use of dedicated Iosipescu strain gauges of specification A2P-08-C085C-500 connected to a data acquisition device, StudentDAQ MM01 in a half-bridge configuration to record the shear strain. The Iosipescu strain gauge has its resistors aligned in the $+45^{\circ}$ and $-45^{\circ}$ directions and are overlapped in a polyamide foil, and hence when connected in a half-bridge network, shear strain is recorded and averaged over the entire length of the Iosipescu notch as

$$
\gamma=\gamma_{+45}-\gamma_{-45}
$$



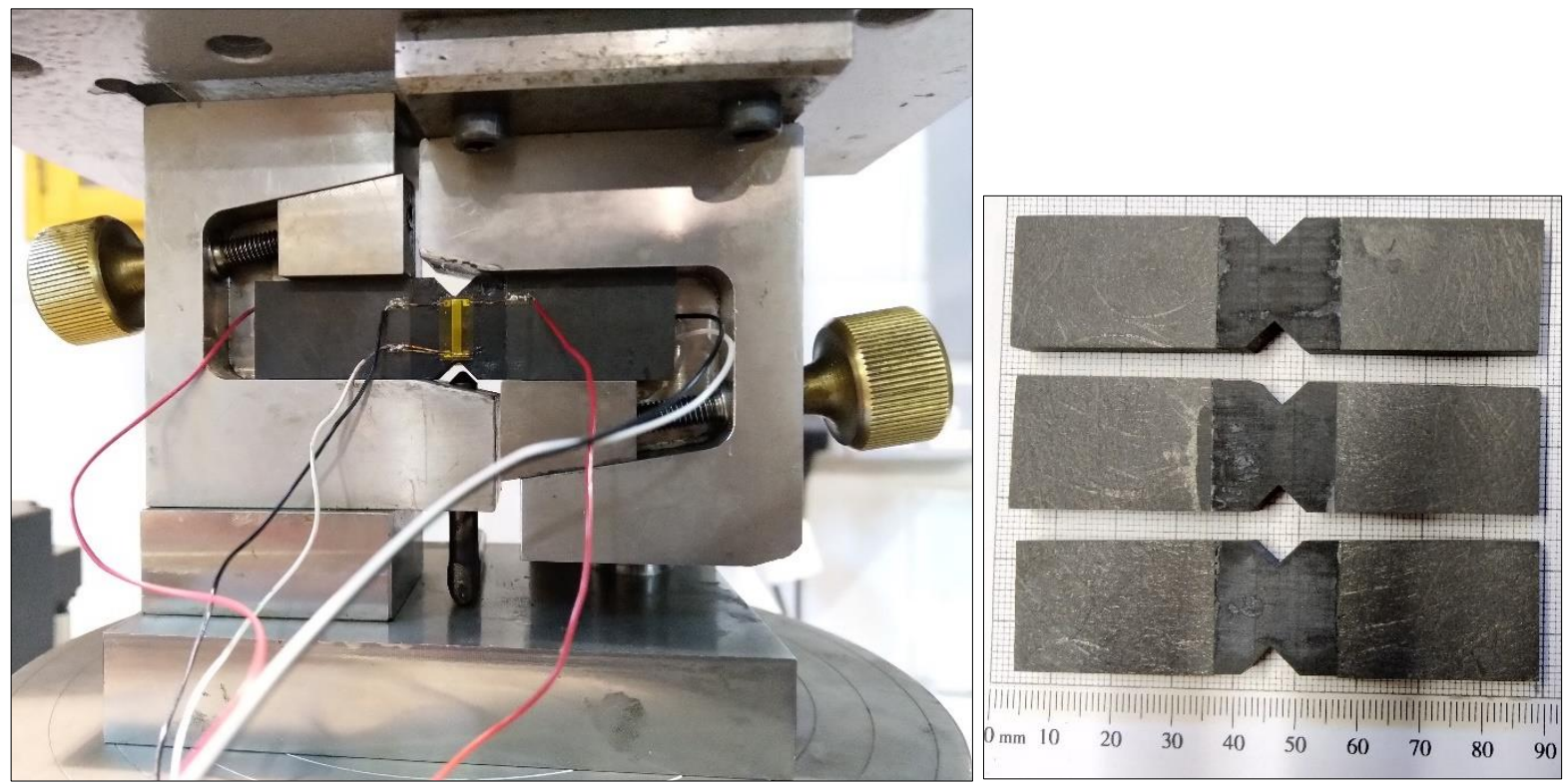

Figure 7 - Iosipescu Shear test apparatus (left) and remanufactured ZX/ZY plane Iosipescu specimens (right)
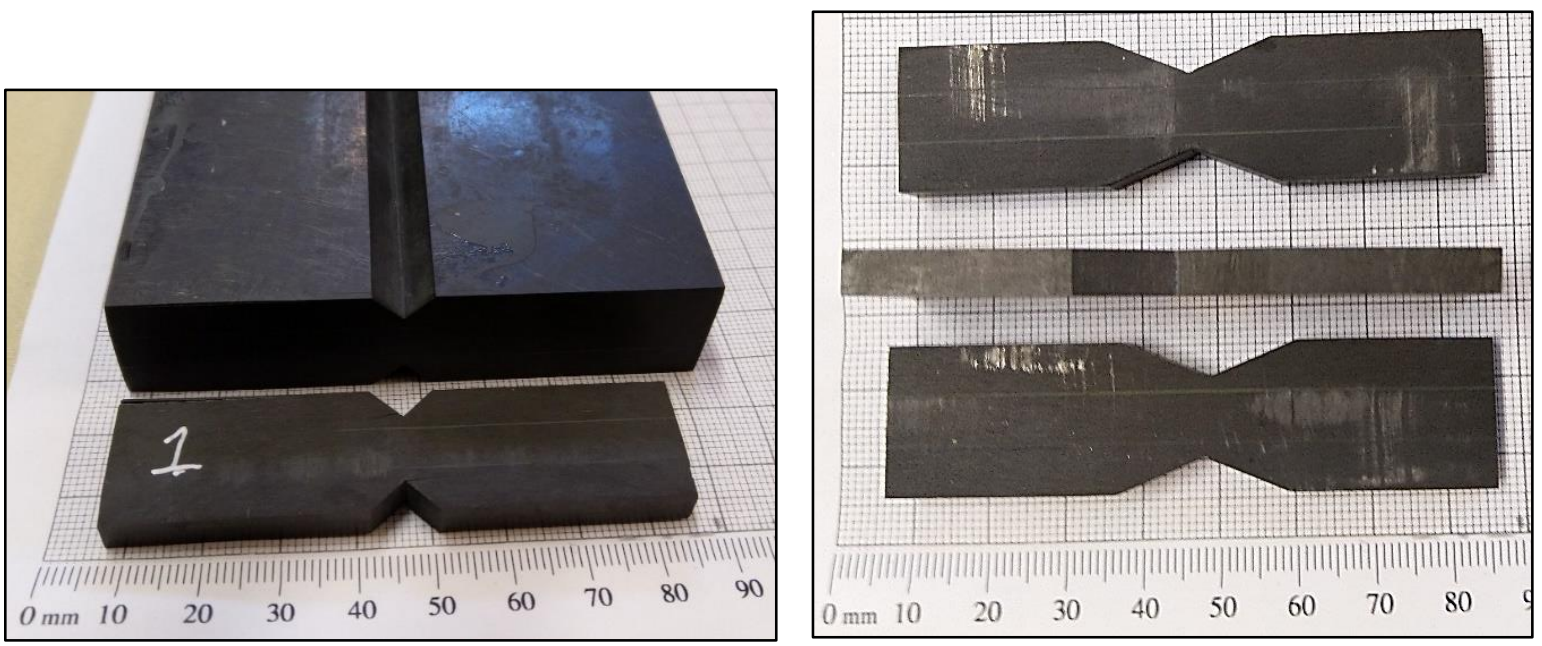

Figure 8 - Remanufactured XZ/YZ plane Iosipescu specimens with $90^{\circ} \mathrm{V}$ notch (left) and $135^{\circ} \mathrm{V}$ notch (right)

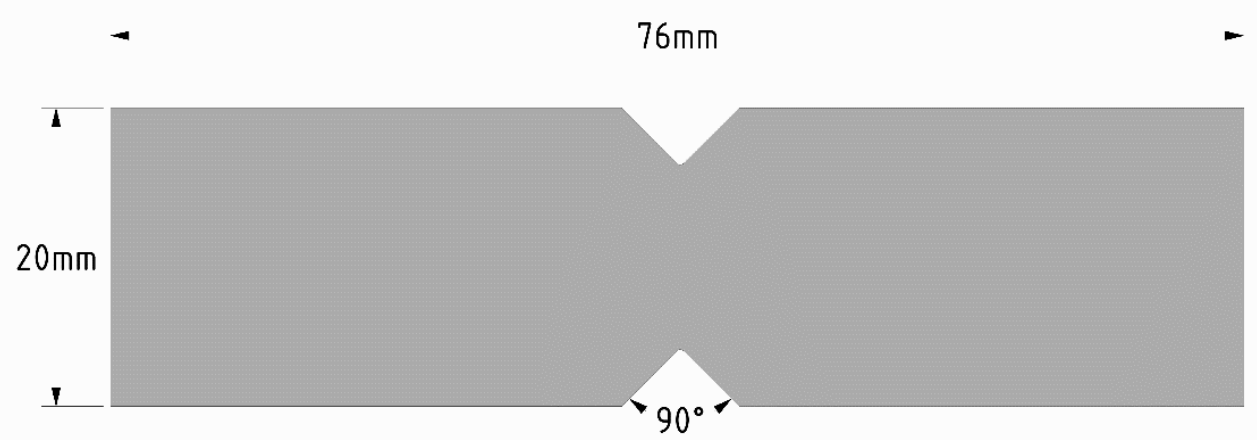



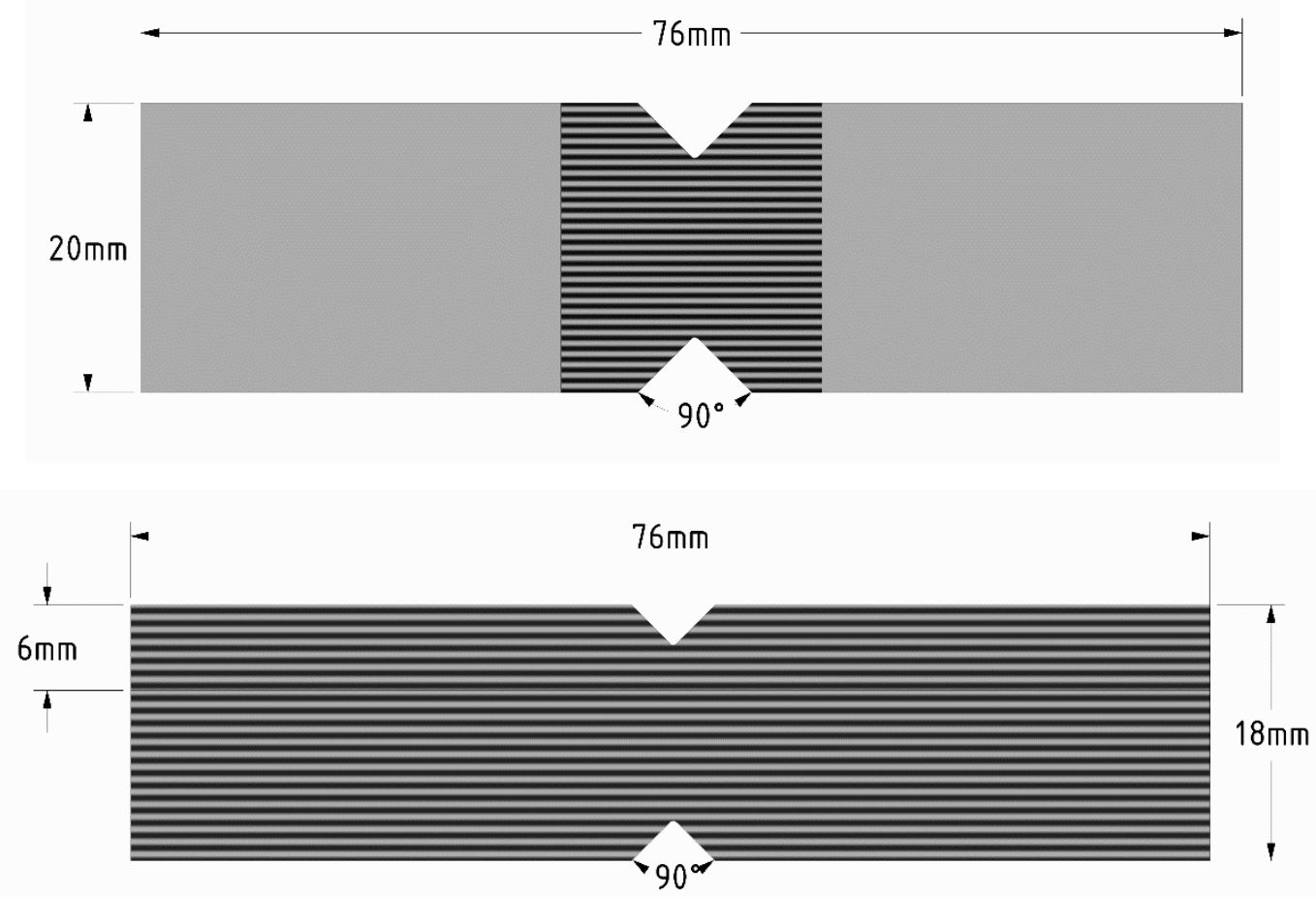

Figure 9 - Representation of Iosipescu specimens in XY plane (top), ZX plane (middle) and XZ plane (bottom)

\section{Results}

The typical failure mode of the laminate when subjected to SBS test in a three point bending set up with both ASTM and ISO standard specifications for both $2 \mathrm{~mm}$ and $6 \mathrm{~mm}$ thick laminate is a tension failure at its bottom plane which is deemed as an unacceptable failure mode. Adaptations to the SBS test as suggested by literature, including the I-beam specimen, use of a sandwich specimen and remanufacture of a thick short beam specimen of $20 \mathrm{~mm}$ thickness comprising of 60 plies, did not induce shear failure in the laminate.

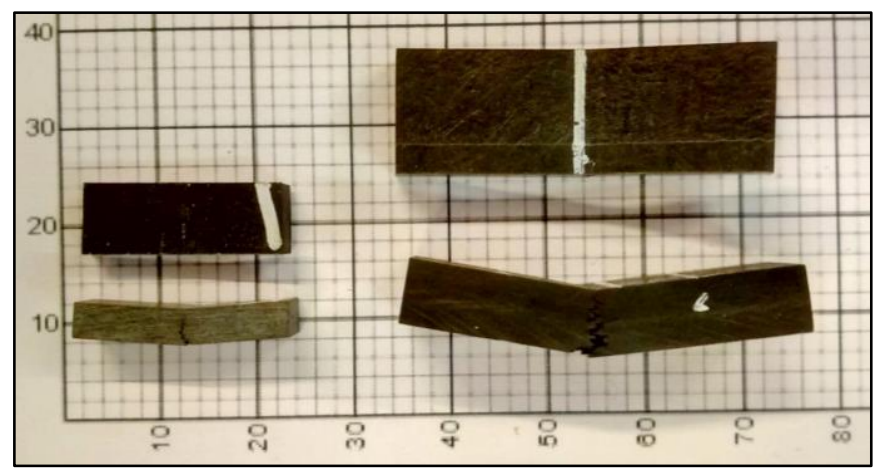



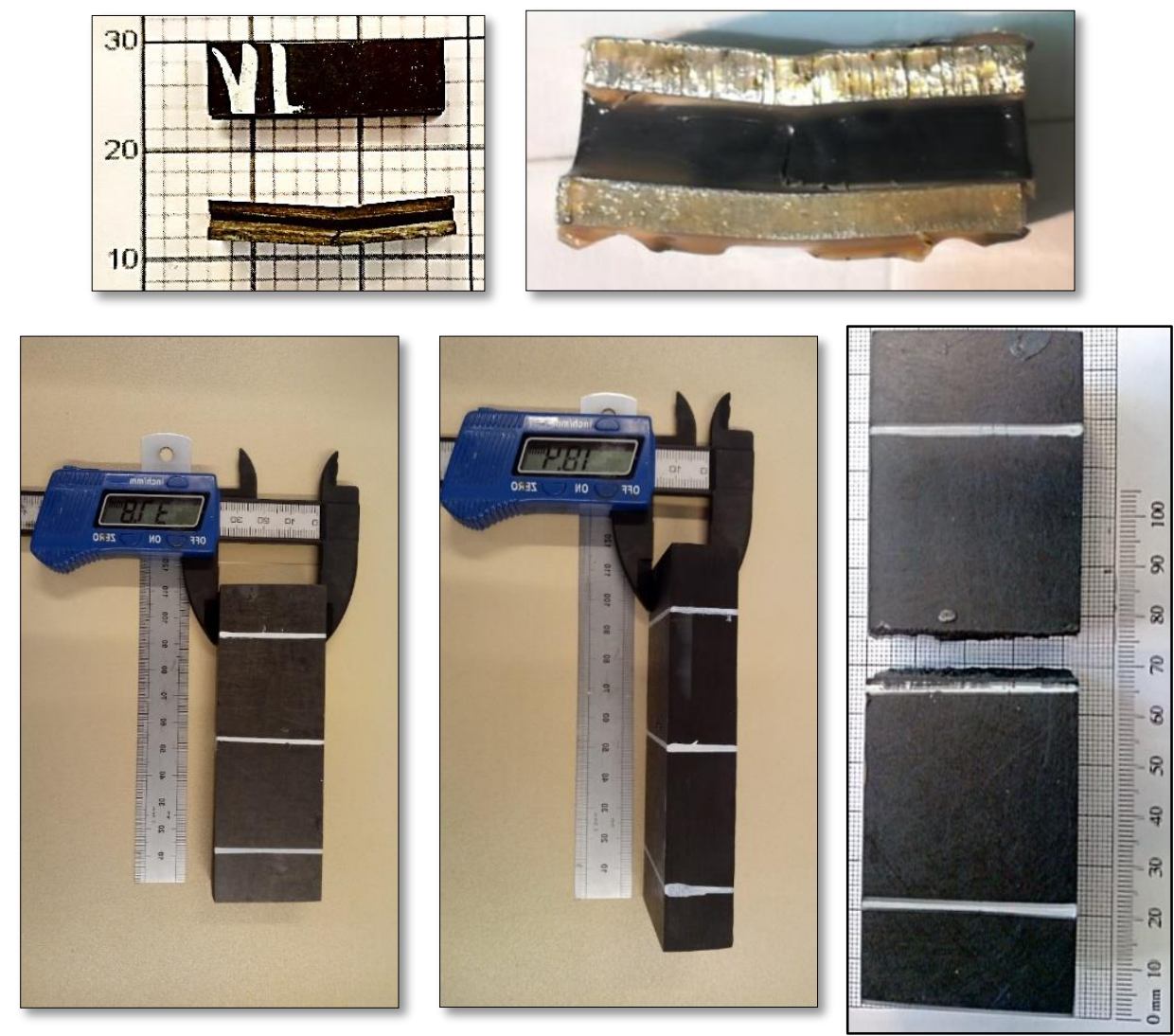

Figure 10 - SBS failed specimen as per standards and modifications to specimen geometry

The DNS test, which was originally designed as an alternative to the SBS test that would not yield acceptable shear failures, uses an axial compressive load to generate a shearing action between the plies in the staggered notched specimen. The compressive load applied the ZX plane resulted in an instantaneous failure with the specimen being crushed at one of the notches instead of an expected delamination crack between the notches as seen in Figure 11.

The apparent shear strength was calculated as the ratio of the failure load to the notch area as a result of the absence of a shear crack plane in the specimens. 


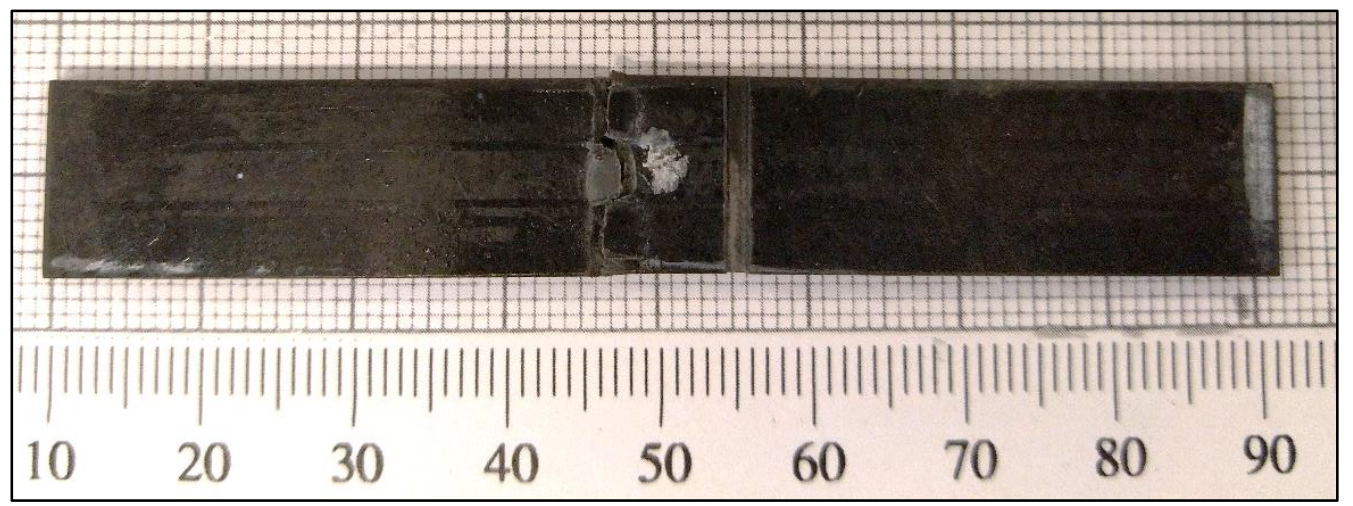

Figure 11 - Failure mode of a DNS specimen

The five point bending load applied on a short beam specimen in the DBS test method subjects the laminate to a complex state of stress. The objective of the DBS test is to induce interlaminar shear failure in the mid-plane of the specimen by means of a delamination between plies or an interlaminar crack in the $\mathrm{XZ}$ plane of the composite material. $33 \%$ of the $2 \mathrm{~mm}$ thick specimens depicted interlaminar cracks in the specimen as shown in Figure 12 whereas the remaining specimens failed by two tensile cracks at the bottom plane in between the support rollers. Although the specimens that depicted interlaminar failure also had cracks at the bottom plane, the delaminations are independent from them. The $6 \mathrm{~mm}$ thick laminates fail catastrophically and none of the specimens tested depicted any signs of shear failure. 

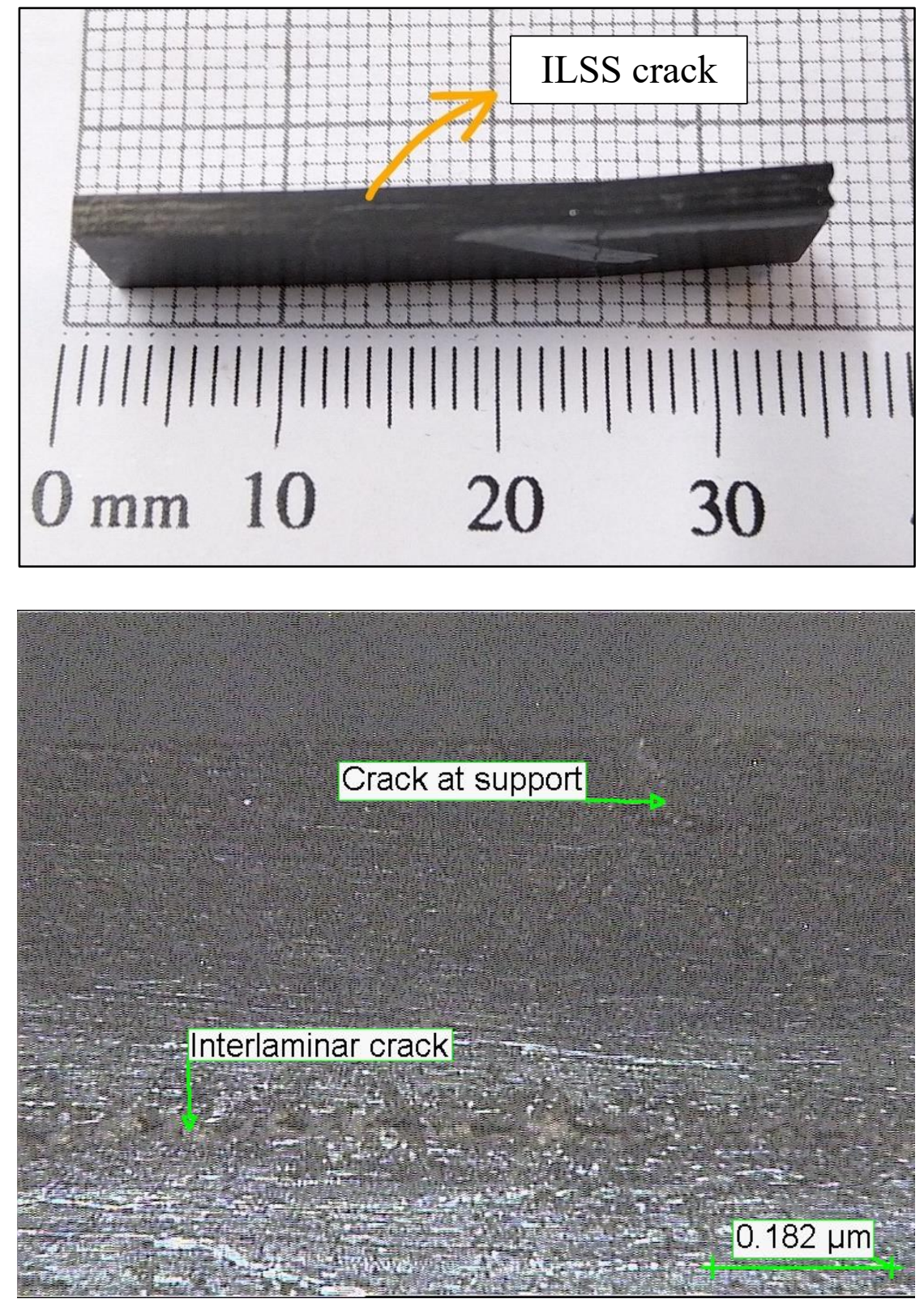

Figure 12 - Interlaminar crack observed with $2 \mathrm{~mm}$ thick laminates

The Iosipescu shear test was conducted on specimens in the $\mathrm{XY}, \mathrm{XZ}$ and ZX planes of the rCF composite laminate as mentioned in the previous section. The XY plane specimens which were utilised to estimate the in-plane shear of the material failed with $45^{\circ}$ tensile cracks between the notches. End tabbing the specimens with GFRP or remanufacturing a thick Iosipescu specimen with thinner critical cross section at the gauge also resulted in a tensile failure. The modifications to the Iosipescu geometry by altering V-notch angles to $60^{\circ}$ 
and $120^{\circ}$, and by reducing the notch to notch distance of the $90^{\circ} \mathrm{V}$ notch have all failed by a tensile crack as shown in Figure 13.

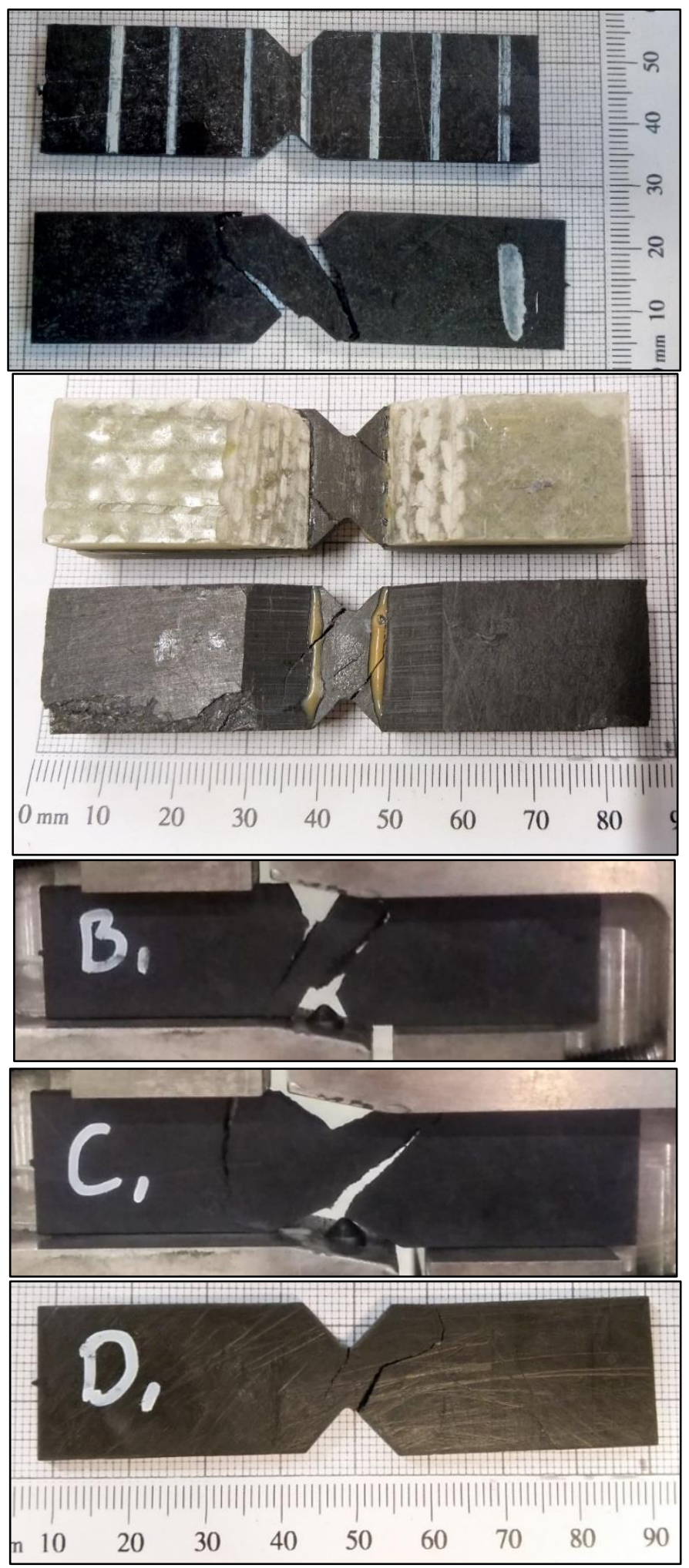

Figure 13 - Typical in-plane shear failure by Iosipescu shear test for standard and modified geometries in XY plane 
The remanufactured specimens tested in the ZY/ZX planes of the composite laminate depicted pure shear failure characterised by a notch to notch shear crack as shown in Figure 14. The shear failure occurred within the laminate in the ZX plane and not at the bond-lines between the cured laminates that confirms the delamination failure in the rCF composite. The interlaminar or the out-of-plane shear strength was calculated at its failure load in these two planes. The shear modulus was estimated with the use of dedicated shear strain gauges bonded between the notches of the specimens that recorded the out of plane shear strain of the material.
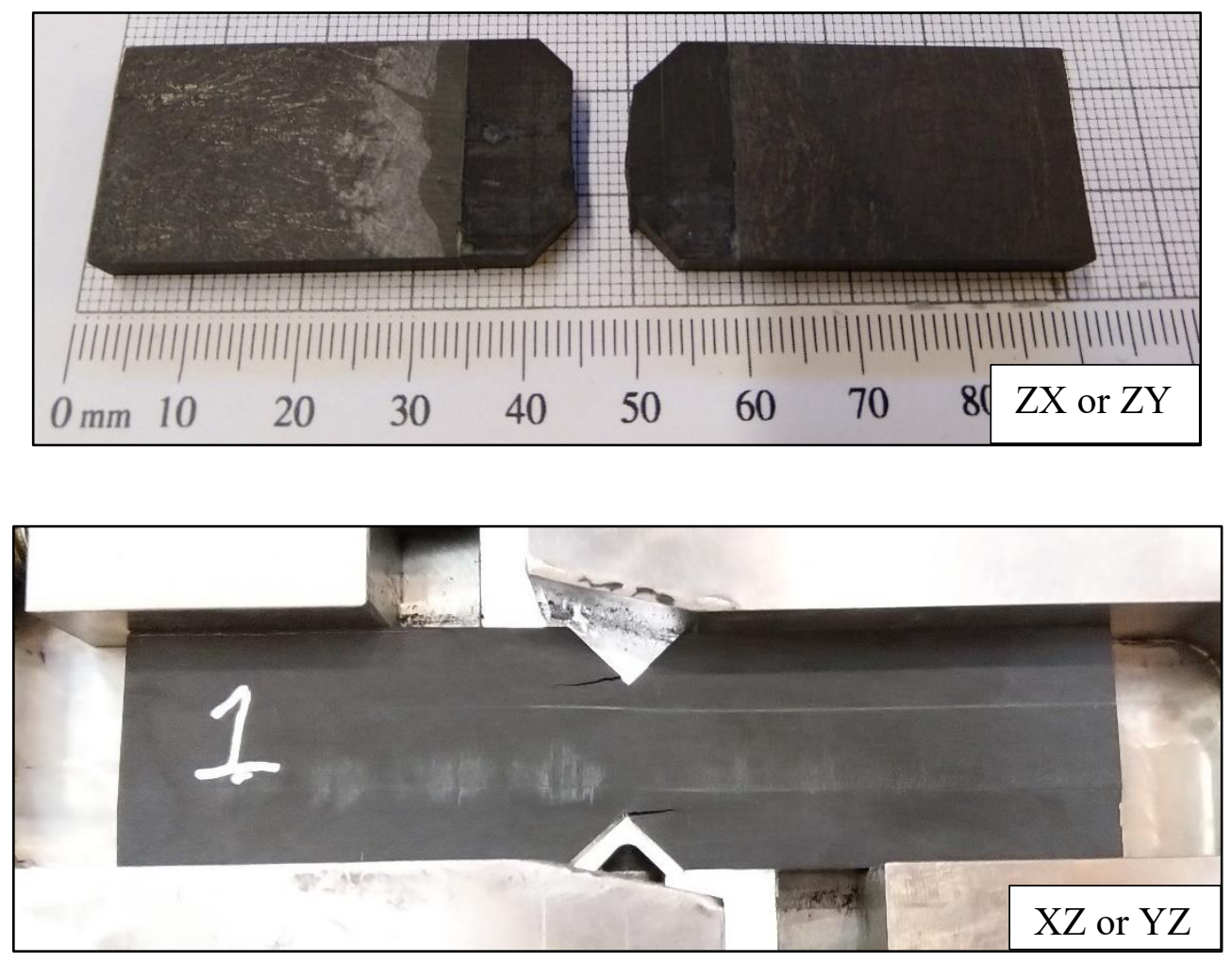

Figure 14 - Typical out-of-plane notch to notch shear failure in ZX/ZY plane (top) and delamination by splitting at the notch in the XZ/YZ plane with $90^{\circ} \mathrm{V}$ notch (bottom)

The specimens tested in the $\mathrm{XZ} / \mathrm{YZ}$ plane with a $90^{\circ} \mathrm{V}$ notch angle failed with delaminations by splitting near the notch. These cracks change the shear stress distribution in its deformed specimen that prevents failure between the notches in the gauge section. The delaminations depicted as a drop in load in the load-displacement curve shown in Figure 16. The cracks 
followed to propagate through the width of the specimen away from the gauge section. The splitting delaminations are also seen with the $135^{\circ} \mathrm{V}$ notch angle specimens as shown in Figure 15. It was observed that the failure strength taken from the first occurrences of laminate splitting of the $135^{\circ} \mathrm{V}$ notch specimens were higher than the $90^{\circ} \mathrm{V}$ notch specimens.

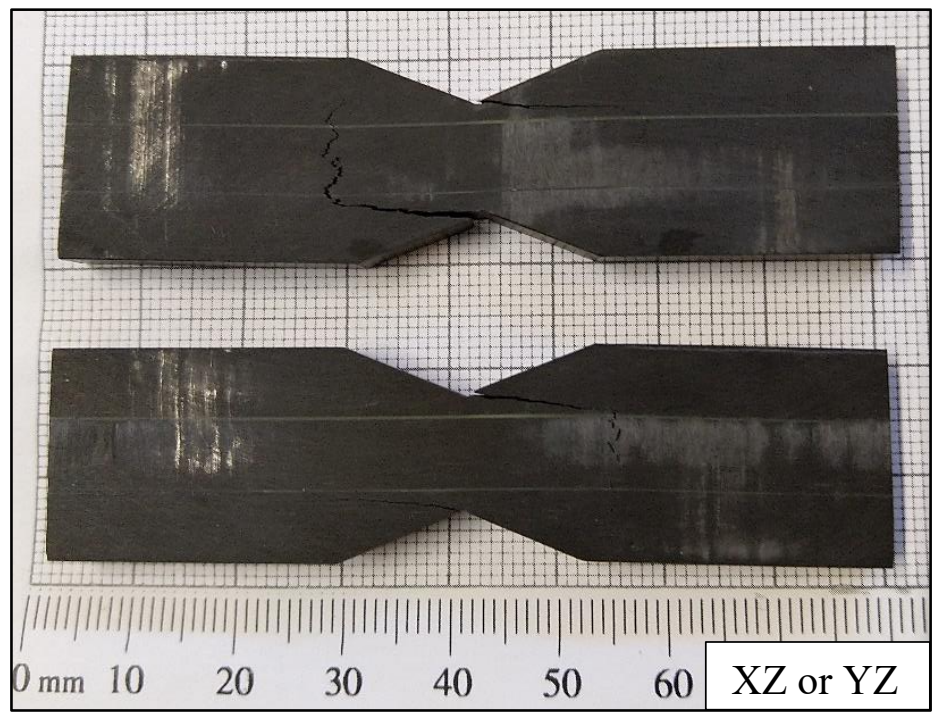

Figure 15 - Laminate splitting in XZ/YZ plane on $135^{\circ} \mathrm{V}$ notch Iosipescu geometry

\begin{tabular}{|c|c|c|c|c|}
\hline S. No. & Shear Test Method & $\begin{array}{c}\text { Failure Stress or } \\
\text { Shear Strength } \\
(\mathrm{MPa})\end{array}$ & Testing Plane & Failure mode \\
\hline 1 & Short Beam Shear (SBS) & $39.90+/-3.97$ & $\mathrm{XZ}$ or YZ & Tensile \\
\hline 2 & Double Notch Shear (DNS) & $30.59+/-3.10$ & ZX or ZY & Crushing \\
\hline 3 & $\begin{array}{c}\text { Double Beam Shear (DBS) } \\
2\end{array}$ & $48.70+/-2.88$ & $\mathrm{XZ}$ or YZ & Shear (33\%) \\
\hline \multirow{2}{*}{4.1} & $\begin{array}{c}\text { Iosipescu Shear } \\
\left(90^{\circ} \text { V notch) }\right.\end{array}$ & $46.90+/-4.96$ & $\mathrm{XZ}$ or YZ & $\begin{array}{c}\text { Delamination/ } \\
\text { splitting }\end{array}$ \\
\cline { 2 - 5 } & $\begin{array}{c}\text { Iosipescu Shear } \\
\left(135^{\circ} \text { V notch) }\right.\end{array}$ & $60.81+/-4.22$ & XZ or YZ & $\begin{array}{c}\text { Delamination/ } \\
\text { splitting }\end{array}$ \\
\hline
\end{tabular}


The shear strengths estimated by the four test methods are summarised in Table 2 . The loadcrosshead displacement plot for the out-of-plane tests is depicted in Figure 16 and for the inplane Iosipescu test in Figure 17. It can be seen that the slopes of the DNS and the Iosipescu tests are linear whereas the SBS and DBS have transition regions during the shear tests.

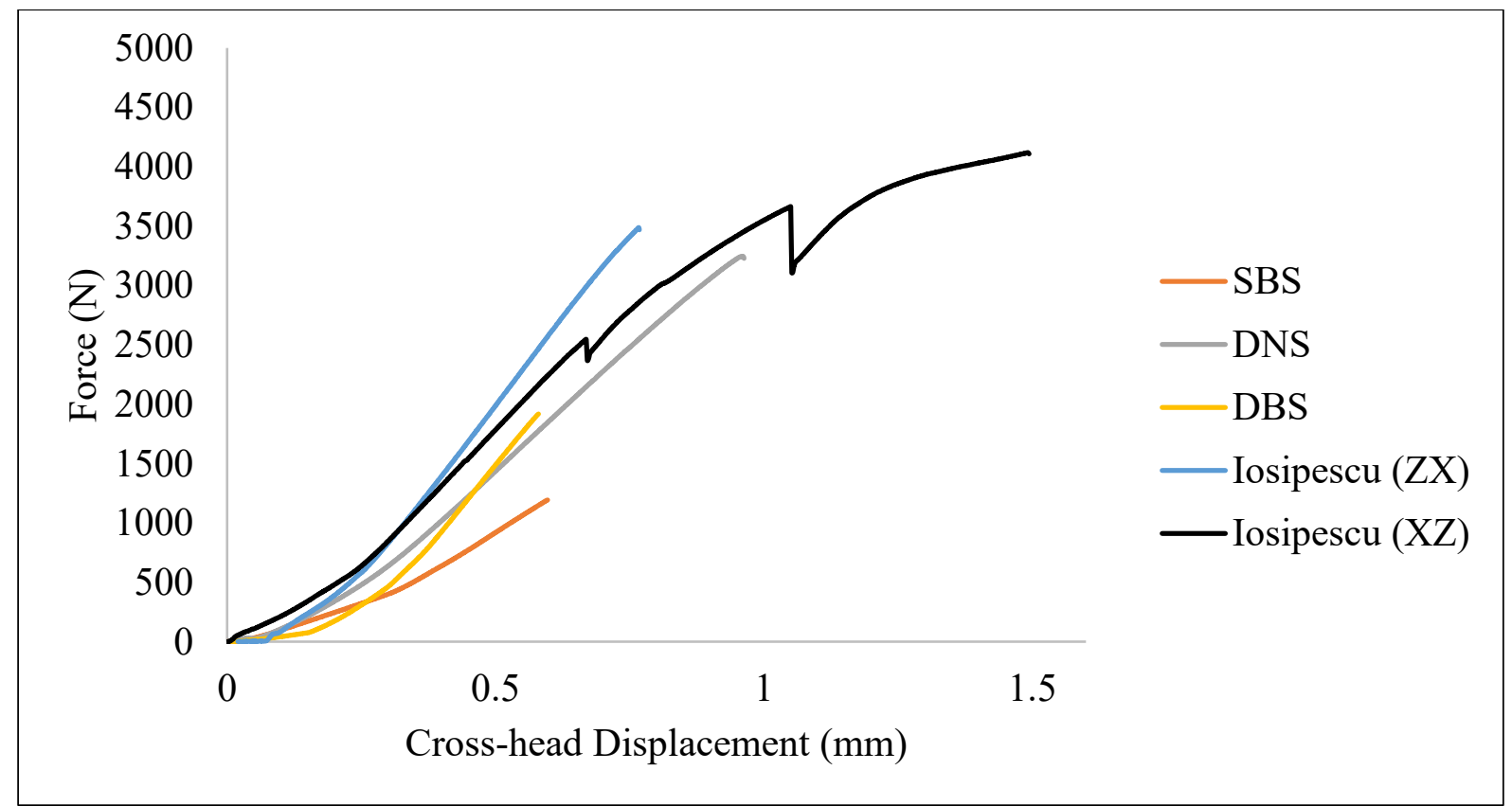

Figure 16 - Load-Crosshead displacement curves for the out-of-plane shear tests

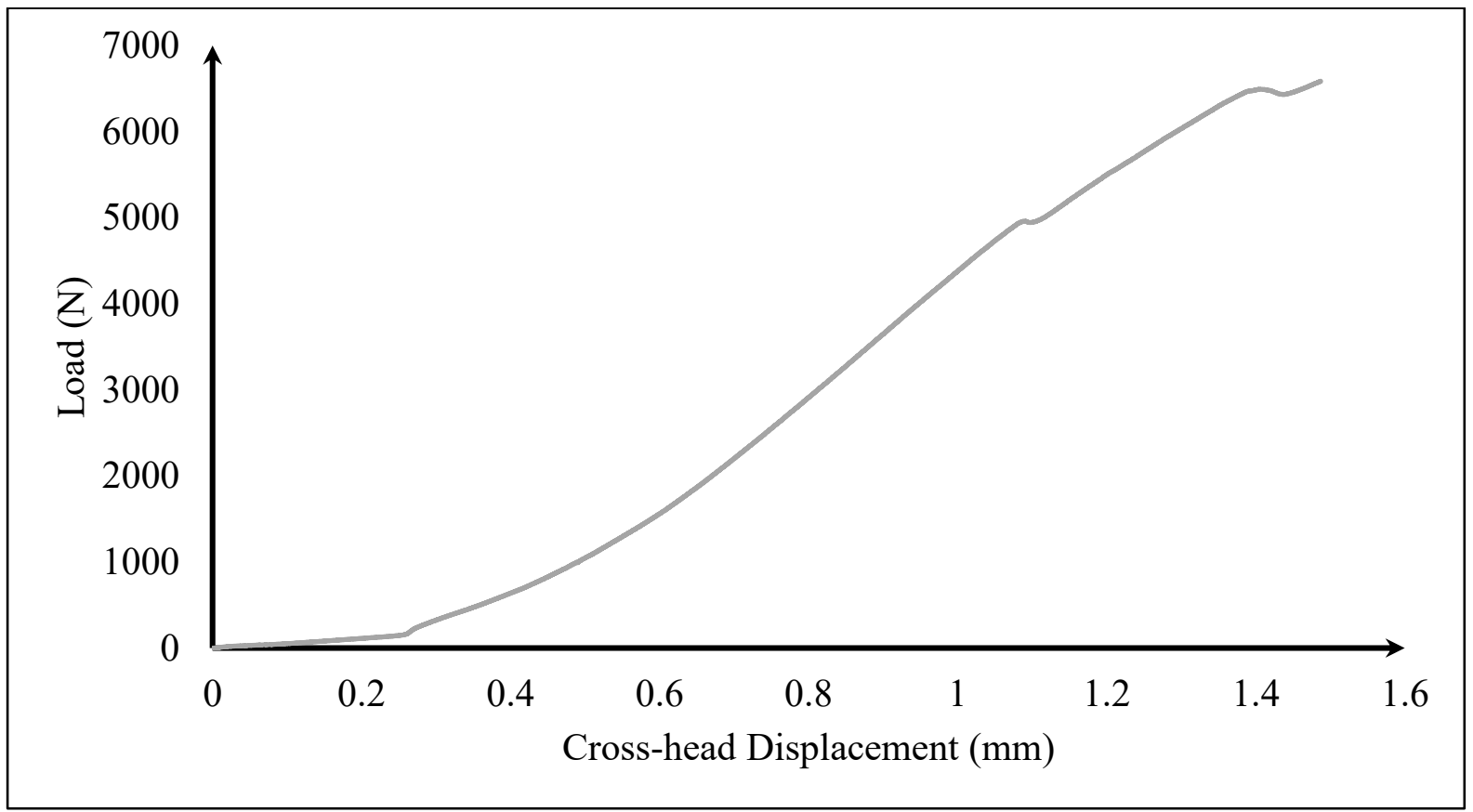

Figure 17 - Load-Crosshead displacement of the Iosipescu in-plane shear test (XY plane) 
The average shear modulus from the Iosipescu shear test in the ZX plane was derived from its stress-strain plot in Figure 18, calculated from the slope of the curves until the failure of the strain gauge and was estimated to be $2.74+/-0.34 \mathrm{GPa}$. The strain gauges de-bonded from the specimen before reaching the failure stress of the composite.

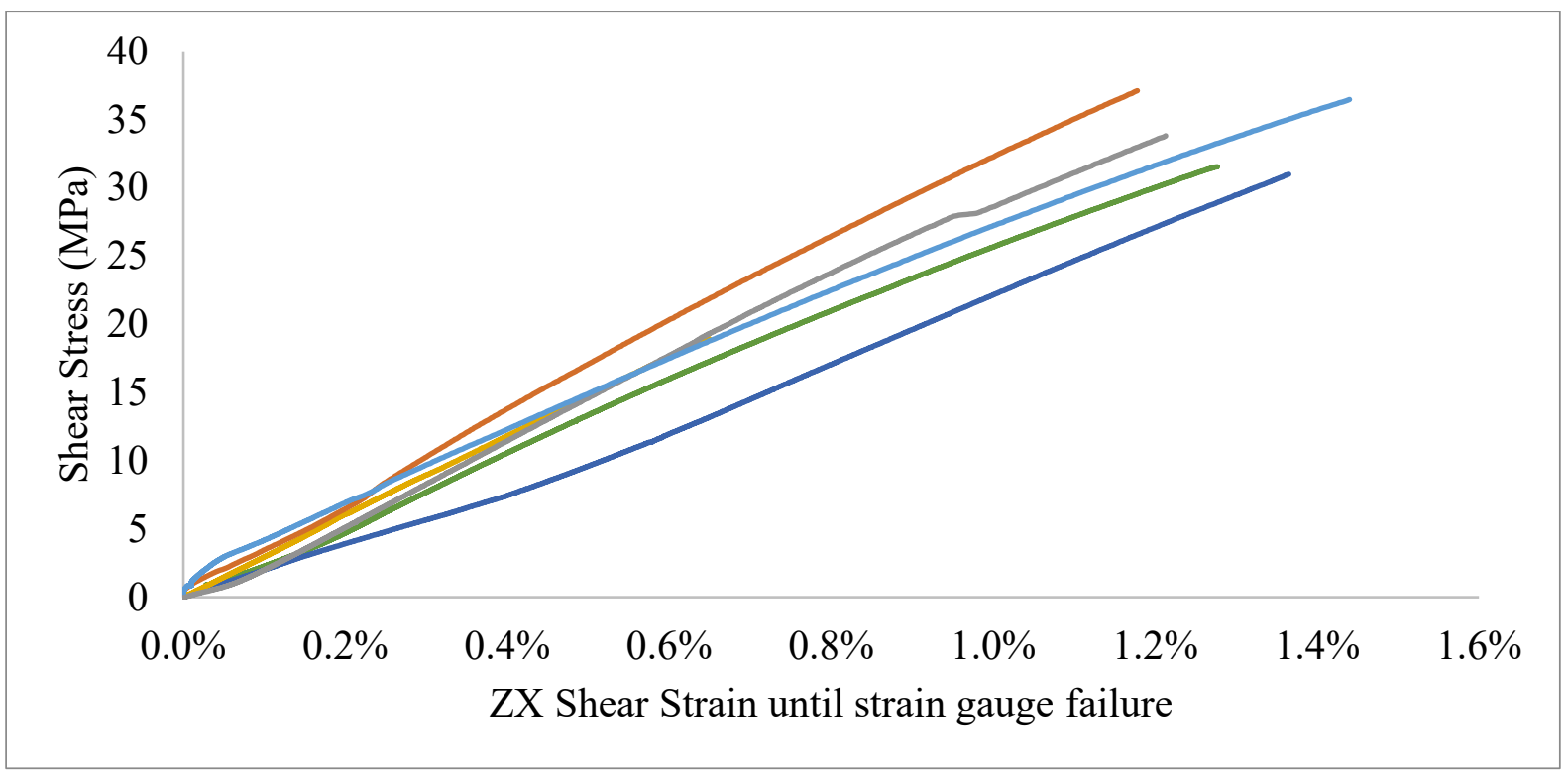

Figure 18 -Shear Stress-Strain curves of Iosipescu shear test in the ZX plane

\section{Discussion}

Analysis of the failure modes in $\mathrm{rCF} / \mathrm{epoxy}$ non-woven composites indicates the pertinence of the above mentioned test methods for this class of materials. The load-displacement curves (Figure 16) shows that the short beam specimens under SBS and DBS have distinct regions where the slope increases after a certain load whereas the Iosipescu and DNS curves are relatively linear in nature. This could possibly be the result of the complex stress states that the SBS and DBS specimens are subjected to during the test. Despite this, the DBS test resulted in 33\% acceptable interlaminar shear failures for $2 \mathrm{~mm}$ thick laminates. The higher fibre volume fraction in $6 \mathrm{~mm}$ thick laminates could have prevented an interlaminar shear failure by DBS. The SBS test, utilised for the characterisation of shear in the XZ or YZ plane, and its modifications including the use of over 60 porous nonwoven plies, the introduction of 
notches and the sandwich beam result in a tensile failure at its bottom plane. This failure mode with SBS is not limited to discontinuous laminates as this has been the commonly reported failure mode with numerous other composite reinforcements too. The advantage of this method has always been the simplicity of the test, ease in the manufacture of the specimens and the fixture and has been adopted as a quick quality check for composites by determining its 'apparent' interlaminar shear strength. The DBS method has been slightly more successful than the SBS method in getting an interlaminar shear failure in the same XZ or YZ planes of the discontinuous nonwoven laminate used here. Similar to the SBS, the DBS test is simple and inexpensive to set up and is a viable alternative to determine the interlaminar shear strength of the material. The disadvantage lies in detecting the interlaminar crack in the material, especially in the rCF/epoxy composite used in this study, and the lower repeatability and success rate in shear failure. The DBS may possibly be less applicable to non-woven laminates with higher fibre volume fraction content as no shear failure was observed in the $6 \mathrm{~mm}$ thick rCF/epoxy composite. The inability of the test to subject the specimen to a pure shear stress state like the Iosipescu or the Arcan test methods means that it is limited to the shear determination in the $\mathrm{XZ}$ or $\mathrm{YZ}$ plane alone.

The DNS test does not result in shear failure in the composite structure used here. This could be because of the non-uniformity of the stress field in the gauge section of the specimen between the notches and the existence of highly concentrated stresses around the manufactured notches that forces the specimen to fail by crushing at the notch in compression. The incapability of the DNS test to generate a uniform shear fracture plane could possibly be because of the nature of the porous nonwoven reinforcement composite that results in a moderately transversely isotropic material in the XY plane [41]. In addition to this, it has been widely reported in literature that the distance between the notches and depth 
of the notches can result in variable results and DNS has very little scope as a shear test alternative at least for the reinforcement structure used in this study.

The use of Iosipescu shear test in the determination of the in-plane shear component along the XY or YX plane of the material did not generate a shear failure that is characterised as a notch to notch crack. Changes to the V-notch geometry of the Iosipescu specimen set at $120^{\circ}$, $60^{\circ}$ and a reduced notch distance have not changed the pattern of the $45^{\circ}$ tensile crack observed. This can be explained by the distribution of the fibres in the XY plane of the laminate that offers resistance in the warp and weft directions which prevents the matrix dominant shear failure in this plane. The influence of the lay-up and fibre distribution is also explained in a continuous fibre reinforced cross-ply [0/90] GFRP/epoxy laminate where different failure modes were observed when tested at different off-axis angles in the Iosipescu test $[30,46]$.

The remanufacture of the laminate to characterise the composite in the ZX or ZY plane resulted in a pure shear failure between the V notches characterised as an instantaneous and straight crack between the notches. This fracture is synonymous to that of a delamination failure between the plies of the cured laminate and is consistent across all of the specimens tested. The shear strength calculated here comply with the out-of-plane or interlaminar shear strength of the material as the gauge region of the Iosipescu specimen is subjected to a state of pure shear. The lesser amount of fibres dispersed in these planes relative to that in the XY plane facilitated a matrix dominated crack. The influence of the epoxy bond between the cured laminates can be negated as the cracks observed occurred within the central laminate and not at the bond-line. The disadvantage is that careful specimen remanufacture can be cumbersome and requires the use of thick cured laminates, of at least $6 \mathrm{~mm}$ in thickness, to minimise the influence of external epoxy bond-lines. ASTM D5379 requires that the laminate must either be at least $76 \mathrm{~mm}$ thick or be co-bonded to $76 \mathrm{~mm}$ thickness [47]. The 
manufacture of a $76 \mathrm{~mm}$ thick laminate is challenging for compression moulding techniques especially on a fabric such as rCF nonwoven mats, that are by nature lofty due to the mechanical bonding enabled by the needle punched fibres in the $\mathrm{Z}$ direction. The hypothetical case of manufacturing a $76 \mathrm{~mm}$ thick laminate would suggest the presence of flaws, defects, voids and a poorly cured material through the thickness of the laminate that would result in poor experimental values. The maximum thickness of the laminate in this study was thus restricted to $6 \mathrm{~mm}$. This ensured a suitably cured laminate through the thickness of the material with minimum manufacturing defects. The alternative option of co-bonding up to 76 $\mathrm{mm}$ thickness was also considered, but this was thought likely to introduce several undesirable variables during the test. Firstly, the bond-lines between the cured laminates has to be minimal to reduce the influence of adhesive in the test. Secondly, co-bonding over 13 cured $6 \mathrm{~mm}$ thick laminates in a laboratory setting without imperfections or misalignments was deemed unlikely. Thirdly, in the case of such a manufactured material, the grips of the $\mathrm{V}$ notch specimen may well undergo some amount of crushing that would also influence the result. Hence, only the critical section of the V notch geometry was manufactured and bonded to laminates in the XY plane, which tend to exhibit higher load resistance than those loaded in the $\mathrm{ZX} / \mathrm{ZY}$ plane, as the results of this study would suggest. The fulfilment of interlaminar shear in the refabricated $\mathrm{V}$ notch specimen was realised with cracks that occurred within the central laminate between the $\mathrm{V}$ notches with the exclusion of any cracks originating from the bond-lines between the cured laminates, as seen in Figure 14. Although the specimen remanufacturing seemed tedious, it remains a valid method for the determination of the critical shear strength in the ZX/ZY plane of rCF composites. The shear modulus was estimated with the use of dedicated shear gauges bonded onto one face of the Iosipescu specimen. The influence of any twisting in the specimen was checked by measuring the shear strains by bonding the strain gauges on both the sides of one Iosipescu specimen. A 
difference of $0.31 \mathrm{GPa}$ in the shear modulus was calculated but this error can be averaged out by the use of a larger sample size. This variance could arise due to errors in bonding alignment of the central gauge section to the remaining sections of the Iosipescu geometry, possible twisting of the specimen by the jig, differences in thickness across the specimen, relatively smaller strain considered (up to $13 \mathrm{MPa}$ load), variability in the distribution of the fibres in the gauge section or the material and errors from the strain gauge itself. However this inconsistency in shear strains from the two faces of the same specimen falls within the standard deviation of the sample considered here.

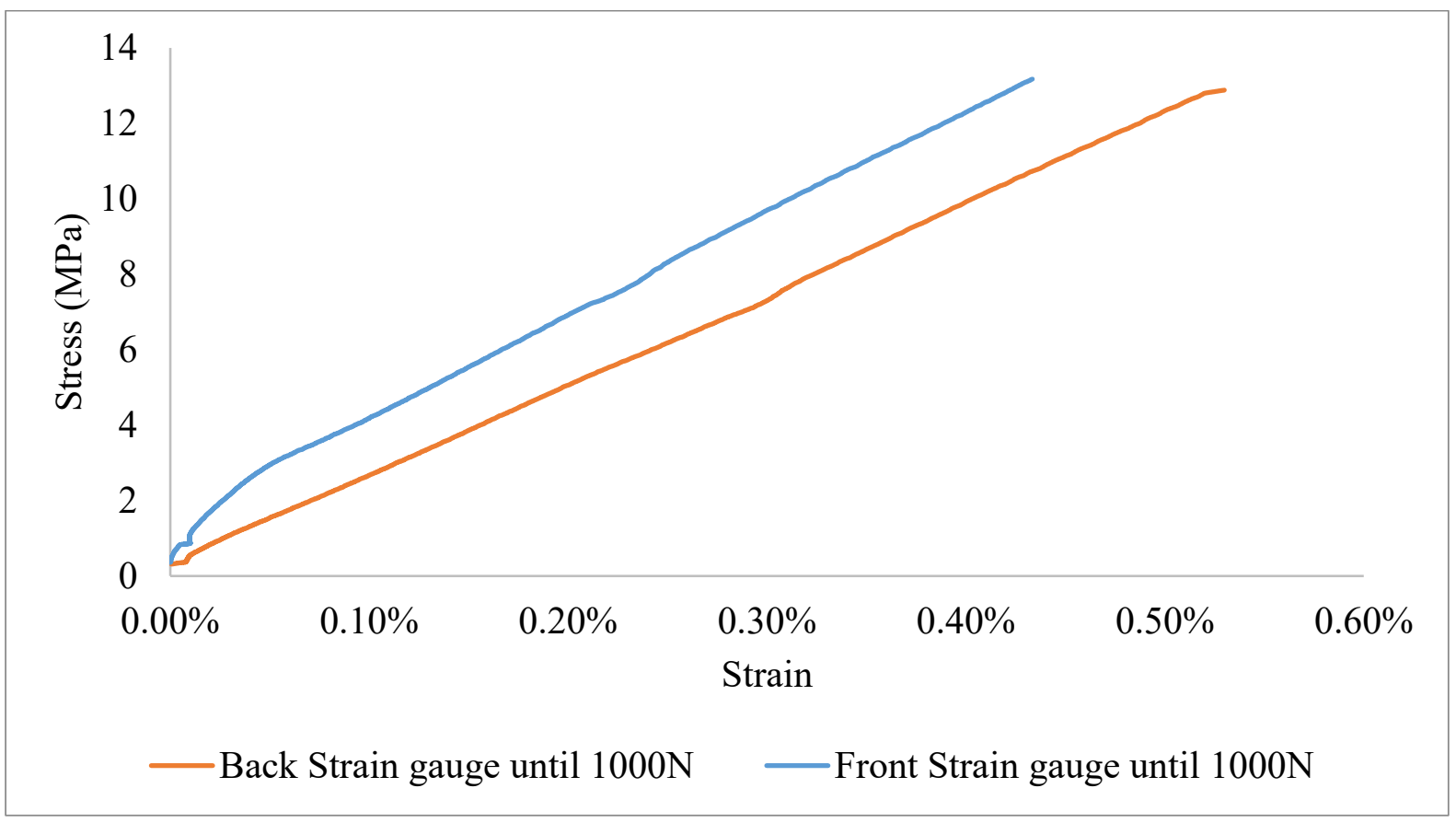

Figure 19 - Shear Modulus calculated from both faces of the ZX/ZY Iosipescu specimen

The delamination failure observed in the $90^{\circ} \mathrm{V}$ notch Iosipescu specimen in the XZ/YZ plane is similar to the failure modes reported in UD composite specimens tested along the $90^{\circ}$ direction $[21,28,37]$. The specimen fails by splitting near the notches before shear failure is observed in the gauge section. Applying shear load along the XZ/YZ planes led to the manifestation of laminate splitting failure in the ZX/ZY planes. The splitting of the top and the bottom laminates, represented by drops in load in Figure 16, is possibly followed by a 
non-uniform stress distribution in the remaining specimen geometry that prevents further delaminations between the $90^{\circ} \mathrm{V}$ notches. Alteration to the angle of the $\mathrm{V}$ notch to $135^{\circ}$ as per Equation 1 do not result in the occurrence of a shear failure, but rather the failure strength of the modified specimen appeared to depend on the angle of the V notch. The dependence of the failure strength on the angle of the $\mathrm{V}$ notch calls for the continued use of the $90^{\circ} \mathrm{V}$ notch as recommended by the international standards. The failure strength was taken as the first occurrence of a delamination crack in the test material, but whether this can be considered as an interlaminar failure is debatable, just as in the case with unidirectional continuous fibre composites discussed in literature [21, 28, 37].

The occurrence and determination of out-of-plane or interlaminar shear failure in a multidimensional reinforced composite such as the discontinuous, non-woven reinforcement discussed here involves the identification of the shear plane in which pure shear failure is likely to occur. Interlaminar failure is likely to occur in the weakest shear plane of the laminate wherein the reinforcement fibres along that particular plane is minimal. The Iosipescu shear test for the determination of interlaminar shear requires a specific fixture, refabrication of planar laminates for manufacturing specimens, bonding of strain gauges for the determination of shear moduli and overall, it becomes a relatively expensive test procedure. Despite this, the use of the Iosipescu test specimen for the out-of-plane shear remains the only viable method that can repeatedly and precisely determine the interlaminar shear strength and shear modulus for rCF composites reinforced with non-woven needle punched fabric composites that can be used as data for design. This refabricated $\mathrm{V}$ notch geometry and test method may also be applicable to textile composites with similar reinforcement architectures. 


\section{Conclusions}

Our research focused on the static shear behaviour of recycled carbon fibre/epoxy composites with discontinuous, non-woven reinforcement architecture under ambient laboratory conditions using four shear test methods. The nature of the internal fibre architecture means that pure shear failures are difficult to realise from conventional testing. The difficulty in obtaining a shear failure was evident with three point bending on a SBS specimen (including modified geometries), and the DNC test. The DBS test by five point bending, provided the occurrence of interlaminar failure, is a simple, inexpensive and quick test which should effectively replace the use of SBS by three point bending in the determination of interlaminar shear intended for quality based assessments only. The DBS test resulted in shear failures in $33 \%$ of the rCF specimens, even though the material was subjected to a complex loading configuration.

The nature of the reinforcement architecture restricts pure in-plane shear failure for the Vnotch Iosipescu shear test. The Iosipescu test seemed to be the most successful for interlaminar shear but the specimen geometry needed to be remanufactured and redesigned with thick laminates so as to observe pure shear failure in the material, introducing load into the weakest planes of the material. Identification of the shear plane in which interlaminar failure is likely to occur was key in the determination of the critical limit of shear strength in rCF composites. With rigorous and careful specimen preparation and remanufacturing procedures, repeatable, reliable and pure interlaminar shear failures, characterised by a notch to notch crack in the $\mathrm{V}$ notch specimens, were observed. We found that the refabricated Iosipescu specimens provided consistent shear failures in the ZX plane, and the Double Beam Shear (DBS) generally resulted in interlaminar shear failure in discontinuous non-woven laminates. Shear modulus of the rCF composite was determined with the aid of dedicated 
strain gauges, which was also used to check for any evidence of specimen twisting during the Iosipescu test for interlaminar shear.

\section{Acknowledgements}

The authors would like to thank ELG Carbon Fibre Ltd. for their financial support of a PhD programme at Oxford Brookes University, and for the supply of cured laminates and technical advice. We thank Mr. Richard Offer, Oxford Brookes University, for his valuable assistance in this project.

\section{References}

[1] Jiang G, Pickering SJ, Lester EH, Turner TA, Wong KH, Warrior NA. Characterisation of carbon fibres recycled from carbon fibre/epoxy resin composites using supercritical npropanol. Composites Science and Technology. 2009;69(2):192-8.

[2] Keith MJ, Oliveux G, Leeke GA. Optimisation of solvolysis for recycling carbon fibre reinforced composites. ECCM17 - 17th European Conference on Composite Materials, Munich, 2016.

[3] Henry L, Schneller A, Doerfler J, Mueller WM, Aymonier C, Horn S. Semi-continuous flow recycling method for carbon fibre reinforced thermoset polymers by near- and supercritical solvolysis. Polymer Degradation and Stability. 2016;133:264-74.

[4] Prinçaud M, Aymonier C, Loppinet-Serani A, Perry N, Sonnemann G. Environmental Feasibility of the Recycling of Carbon Fibers from CFRPs by Solvolysis Using Supercritical Water. ACS Sustainable Chemistry \& Engineering. 2014;2(6):1498-502.

[5] Piñero-Hernanz R, Dodds C, Hyde J, García-Serna J, Poliakoff M, Lester E, et al. Chemical recycling of carbon fibre reinforced composites in nearcritical and supercritical water. Composites Part A: Applied Science and Manufacturing. 2008;39(3):454-61.

[6] Oliveux G, Bailleul J-L, Le Gal La Salle E, Lefèvre N, Biotteau G. Recycling of glass fibre reinforced composites using subcritical hydrolysis: Reaction mechanisms and kinetics, influence of the chemical structure of the resin. Polymer Degradation and Stability. 2013;98(3):785-800.

[7] Yip HLH, Pickering SJ, Rudd CD. Characterisation of carbon fibres recycled from scrap composites using fluidised bed process. Plastics, Rubber and Composites. 2002;31(6):278-82.

[8] Pickering SJ. Recycling technologies for thermoset composite materials - current status. Composites Part A: Applied Science and Manufacturing. 2006;37(8):1206-15.

[9] Pickering S, Turner T, Meng F, Morris C, Heil J, Wong K, et al. Developments in the fluidised bed process for fibre recovery from thermoset composites 2nd Annual Composites and Advanced Materials Expo, CAMX 2015, Dallas, 2015.

[10] Kumar KK, Heath D, Hutchinson A. Development of design data for discontinuous carbon fibre composites. SAMPE Europe Conference. Southampton 2018.

[11] Holmes M. Recycled carbon fiber composites become a reality. Reinforced Plastics. 2018;62(3):148-53. 
[12] Gehr M. Method and device for recovering carbon fibres from carbon-fibre containing plastics. Pub. No.: US20160060535A1. Google Patents; 2016.

[13] Nilakantan G, Nutt S. Reuse and upcycling of aerospace prepreg scrap and waste. Reinforced Plastics. 2015;59(1):44-51.

[14] ELG Carbon Fibre Ltd., Carbon fibre nonwoven mats. 2017.

[15] Carlsson L, Adams D, Pipes R. Basic experimental characterization of polymer matrix composite materials. Polymer Reviews. 2013;53(2):277-302.

[16] Harris T, Pond B. The Importance of Shear Testing in Process Design, Quality Control. Quality Magazine 2012.

[17] ISO BS EN 14130, Fibre-reinforced plastic composites-Determination of apparent interlaminar shear strength by short-beam method. British Standards International. 1998.

[18] ASTM D2344 / D2344M-16, Standard Test Method for Short-Beam Strength of Polymer Matrix Composite Materials and Their Laminates, ASTM International, West Conshohocken, PA, 2016.

[19] ASTM D3846-08(2015), Standard Test Method for In-Plane Shear Strength of Reinforced Plastics, ASTM International, West Conshohocken, PA, 2015.

[20] ASTM D638-14, Standard Test Method for Tensile Properties of Plastics, ASTM International, West Conshohocken, PA, 2014.

[21] Melin LG, Neumeister JM, Pettersson KB, Johansson H, Asp LE. Evaluation of four composite shear test methods by digital speckle strain mapping and fractographic analysis. Journal of Composites, Technology and Research. 2000;22(3):161-72.

[22] International Organization for Standardization, Plastics : determination of tensile properties : Pt. 4, Test conditions for isotropic and orthotropic fibre-reinforced plastic composites. Genève: International Organization for Standardization; 1997.

[23] Feraboli PJ, Kedward KT. In search of the true interlaminar shear strength. Nineteenth technical conference of the joint American society for composites/American society for testing and materials committee 2007.

[24] Whitney J, Browning C. On short-beam shear tests for composite materials. Experimental Mechanics. 1985;25(3):294-300.

[25] Short SR. Characterization of interlaminar shear failures of graphite/epoxy composite materials. Composites. 1995;26(6):431-49.

[26] "Homepage, Brenntag UK \& Ireland." Brenntag, www.brenntag.com/uk-ireland/en.

[27] Neumeister JM, Melin LN. A modified iosipescu test for anisotropic composite panels. Society of Manufacturing Engineers 2004:121-9.

[28] Bru T, Olsson R, Gutkin R, Vyas GM. Use of the Iosipescu test for the identification of shear damage evolution laws of an orthotropic composite. Composite structures. 2017; 174:319-28.

[29] Almeida Jr JHS, Angrizani CC, Botelho EC, Amico SC. Effect of fiber orientation on the shear behavior of glass fiber/epoxy composites. Materials \& Design (1980-2015). 2015;65:789-95.

[30] Khashaba U. In-plane shear properties of cross-ply composite laminates with different offaxis angles. Composite structures. 2004;65(2):167-77.

[31] Manhani LGB, Pardini LC, Levy Neto F. Assessement of tensile strength of graphites by the Iosipescu coupon test. Materials Research. 2007;10(3):233-9.

[32] Fajrin J, Sari NH. Shear properties evaluation of natural fibre reinforced epoxy composites using V-notch shear test. MATEC Web of Conferences, 2018.195.

[33] Tarnopol'skii YM, Arnautov A, Kulakov V. Methods of determination of shear properties of textile composites. Composites Part A: Applied Science and Manufacturing. 1999;30(7):879-85. 
[34] Zhou G, Green ER, Morrison C. In-plane and interlaminar shear properties of carbon/epoxy laminates. Composites Science and Technology. 1995;55(2):187-93.

[35] Bradley LR, Bowen CR, McEnaney B, Johnson DC. Shear properties of a carbon/carbon composite with non-woven felt and continuous fibre reinforcement layers. Carbon. 2007;45(11):2178-87.

[36] Gipple K, Hoyns D. Measurement of the out-of-plane shear response of thick section composite materials using the V-notched beam specimen. Journal of composite materials. 1994;28(6):543-72.

[37] Melin LN, Neumeister JM. Measuring constitutive shear behavior of orthotropic composites and evaluation of the modified Iosipescu test. Composite structures. 2006;76(12):106-15.

[38] Markham MF, Dawson D. Interlaminar shear strength of fibre-reinforced composites. Composites. 1975;6(4):173-6.

[39] Shokrieh MM, Lessard LB. An Assessment of the Double-Notch Shear Test for Interlaminar Shear Characterization of a Unidirectional Graphite/Epoxy under Static and Fatigue Loading. Applied Composite Materials. 1998;5(5):289-304.

[40] Neumeister JM, Pettersson KB. Analysis of the Inclined Double Notch Shear Test for Composite Interlaminar Shear Properties. CompTest 2003. Châlons en Champagne 2003.

[41] Dadras P, McDowell JS. Analytical and experimental evaluation of double-notch shear specimens of orthotropic materials. Experimental Mechanics. 1990;30(2):184-9.

[42] Wilson D, Carlsson LA. Mechanical Testing of Fiber-Reinforced Composites. In: Kuhn H, Medlin D, Committee AIH, editors. Mechanical Testing and Evaluation: ASM International 2000 .

[43] Kumar KK. Approaches to determine the constituent elements of discontinuous fibrereinforced polymer composites. Research student conference 2018: Oxford Brookes University, Oxford; 2018. p. 54-60.

[44] ELG Carbon Fibre Ltd., Technical Note 1701: Nomenclature for recycled Carbon Fibres. 2017.

[45] Adams D. The Double-Notch Shear test specimen for composite materials Composites World 2013.

[46] Selmy AI, Elsesi AR, Azab NA, Abd El-baky MA. In-plane shear properties of unidirectional glass fiber (U)/random glass fiber (R)/epoxy hybrid and non-hybrid composites. Composites Part B: Engineering. 2012;43(2):431-8.

[47] ASTM D5379 / D5379M-12, Standard Test Method for Shear Properties of Composite Materials by the V-Notched Beam Method, ASTM International, West Conshohocken, PA, 2012. 